\title{
What Happens to Travel Behaviour When the Right to Park is
}

\section{Removed?}

Dr Steve Melia*

Centre for Transport and Society

University of the West of England, Bristol,UK

Dr Ben Clark

Centre for Transport and Society

University of the West of England, Bristol,UK

* Coldharbour Lane, Bristol BS13 1QY. Email: steve.melia@uwe.ac.uk 


\title{
What Happens to Travel Behaviour When the Right to Park is Removed?
}

\begin{abstract}
What happens to travel behaviour when the right to park at a destination is removed? This question, fundamental to travel demand management and land-use planning, has only been partially addressed in the literature so far. The impacts on travel to the destination concerned have been studied, but not the impacts on wider travel behaviour. This paper reports on a natural experiment related to destination parking, where a university removed the right of most undergraduates living off-campus to park on its main suburban campus. A survey was conducted to compare the travel behaviours of two groups of undergraduate students: the first group started before and the second group started after the introduction of the parking restriction ( $\mathrm{n}=858$ ). The survey captured licence-holding, car availability during the term and vacation periods, and the mode of transport used to travel to campus and for the last trip to another location. The parking restriction was associated with a fall in the modal share of driving to campus of nine percentage points. Car availability during term-time fell by 14 percentage points and licence-holding fell by nine percentage points. The policy change was associated with greater changes amongst females than males. Overall, the results suggest that removing the right of young adults to park at a frequent destination delayed their acquisition of driving licences and cars. These findings may explain part of the fall in licence-holding observed amongst young adults in Great Britain in recent decades.
\end{abstract}

Keywords: parking; parking restrictions; behaviour change; modal shift; gender differences; university campuses;

\section{Introduction and Context}

What happens to travel behaviour when the right to park at a destination is removed? This question, fundamental to sustainable transport and land-use planning, has only been partially addressed. Parking restraint at a destination can reduce driving to that destination; that is fairly well established (e.g. Cairns et al., 2010, Petrunoff et al., 2015). Residential parking restraint can reduce car ownership and reduce the modal share of driving amongst those residents; that is also fairly well established (e.g. McCahill et al., 2015, Guo, 2013). Whether parking restraint at a frequent destination 
can also influence car ownership, licence-holding and wider travel behaviour has not yet been studied.

The study reported in this paper evaluated a natural experiment, where a university removed the right of undergraduates living off-campus in a defined area "the no-permit zone" to park on its main suburban campus. Two groups of undergraduates, one starting before and one starting after the introduction of the new parking policy were surveyed. This paper reports on the differences in the travel behaviour, car availability and licence-holding of the two groups of students and reflects on the implications for parking policy and travel demand management. The findings shed important new light on the potential for, and the unintended consequences of, parking restraint as a tool for reducing car use and promoting the use of alternative modes.

The following section reviews the relevant literature and identifies the knowledge gap this study aimed to fill. Section 3 explains how and why the changes in parking policy were introduced on the university campus. Section 4 describes the method and the results are then summarised in Section 5. Section 6 provides a discussion of the findings and their implications. The conclusions are presented in Section 7.

\section{Literature Review}

\subsection{Parking and Transport Policy}

Constraining the availability of parking is a controversial method of managing travel demand. On one side of the debate Newman and Kenworthy (1999) argue that parking constraint has been an important factor in those cities, such as Copenhagen, which have succeeded in reducing automobile dependence. On the other side, the RAC Foundation (2005) argue that motorists value the "flexibility and freedom" provided by 
residential parking. They noted little evidence to support the view that parking restraint would reduce car ownership; it was more likely that parking pressures would "intensify and spread more widely" (RAC Foundation 2005; page 28). Thus a normative political debate often focusses on empirical questions about the effectiveness of parking measures as demand management tools.

The empirical literature has established several links between parking conditions and different aspects of travel behaviour. This study concerns changes to destination parking and this is the central focus of the literature review. However, the wider body of literature on parking and travel behaviour, including residential parking, is also briefly considered.

\subsection{Parking and Travel Behaviour}

A large body of literature has examined the relationship between parking availability (residential or total), land-use and travel behaviour. This has typically found that cities or neighbourhoods with more parking tend to have higher car ownership and use, whilst parking constraints are associated with lower car ownership and use. Some of these studies have used stated preference methods (e.g. Guo, 2013); some have used cross-sectional data (e.g. Weinberger, 2012, Melia, 2014) or hypothetical modelling (Li et al., 2007) and others have analysed aggregate trends over time (e.g. McCahill and Garrick, 2014, McCahill et al., 2015). The last two confirm the expected impacts of gradual increases or gradual reductions in parking capacity on citywide modal share.

Several studies of travel behaviour change interventions have found that changes in parking availability or cost can exert a significant impact on the modal choice of travel to that destination. Some studies have used stated preference methods to estimate the impacts of increasing the price of parking or extending parking controls in city 
centres, generally finding a negative impact on rates of driving (Rye et al., 2006, Kelly and Clinch, 2006, Hensher and King 2001). A cross-sectional study of workplaces in Cambridge, England, found that free workplace parking increases the likelihood of driving to work by a factor of 1.8 (Carse et al., 2013) .

A few studies have compared travel behaviour before and after changes to destination parking. In a study of UK employers that had implemented workplace travel plans, Cairns et al.,(2010) found that organisations which had constrained workplace parking or increased its cost reduced the modal share of driving to work by an average of 25 percentage points. This was more than double the reduction achieved by organisations that attempted to reduce driving without changing their parking practices. A panel study of employment sites in north Bristol, which included the university campus examined in our study, found greater parking availability encouraged modal switches towards single occupancy car use (Chatterjee et al., 2016). Petrunoff $e t$ al. (2015) evaluated a natural experiment of two hospital sites in Perth, Australia, both of which introduced positive incentives to reduce driving whilst only one reduced the availability of parking; the site with reduced parking reduced the modal share of driving to work alone by 42 percentage points, compared to a reduction of just five percentage points for the other site. None of these studies sought to assess the impact of these changes on car ownership or other aspects of travel behaviour, however.

A few studies have analysed the impact of parking and other travel demand measures on university campuses. Riggs (2014) analysed a stated preference questionnaire issued to staff and students at the University of California. This confirmed cost and availability of parking as two factors amongst several that influenced decisions of staff and students not to drive; only six percent of students drove to those urban campuses. Using cross-sectional data, Whalen et al. (2013) found 
that purchase of a student parking permit was a strong predictor of driving to McMaster University in Canada. The permits effectively gave the holder a zero marginal cost of parking once purchased and also indicated a commitment to future car use.

\subsection{Licence-Holding and the Changing Travel Behaviour of Young Adults}

To our knowledge, no studies have examined the relationship between parking availability at regularly visited destinations and licence-holding. This issue is particularly relevant in respect of young adults. It has been observed that the proportion of young adults holding driving licences has declined over the last two decades in many industrialised nations (Berrington and Mikolai 2014), with the reduction occurring mainly amongst young males. These observations have contributed to a wider debate around "peak car", the tentative hypothesis that a structural change has occurred, which will lead to lower levels of car ownership and use in the future (e.g. Goodwin, P. and Van Dender, K., 2013). Thus licence-holding and car ownership amongst young adults have become important issues for transport planning as a whole.

The changes in licence-holding amongst young adults in the UK have been substantial. In England in 1991-3, 60 percent of males and 41 percent of females aged 17-20 held a driving licence; by 2015 this had fallen to 33 percent and 32 percent respectively (DfT 2015). Similar trends have been observed in other developed countries. Several explanations have been advanced for these trends, including rising rates of participation in higher education and an increasing tendency for young adults to live in inner urban areas (Chatterjee et al. 2018). The possible influence of parking constraints on those relationships has not been specifically analysed as yet. 


\subsection{Knowledge Gap and Research Questions}

A wider search of the literature failed to identify any studies of the impact of changes in parking availability at destinations on car ownership or licence-holding. Whether changes in parking arrangements at one destination can influence modal shares in travel to other destinations is also unknown. Thus it seems that questions fundamental to policy debates around travel demand management have only been partially addressed. This prompted the following research questions for this study:

1) What was the impact of removing the right to park on campus from most students on the mode of travel to campus?

2) What was the impact of removing the right to park on campus from most students on their wider travel behaviour including: car ownership, licence-holding and the mode of travel to other places for other purposes?

\section{Study Context}

This study was conducted at the University of the West of England's (UWE's) Frenchay campus where a change in parking policy created a natural experiment, offering the opportunity to evaluate associated changes in travel behaviour.

Frenchay campus is located in a suburban area, on a major ring road, roughly four miles north of the centre of Bristol, a city with a population of around 600,000. The main roads around the campus are heavily congested at peak times. The campus has been expanding in recent years with substantial growth of student accommodation and some departments transferred from another site. In order to obtain planning permission for several new buildings, UWE has been required to demonstrate how the site can be intensified without increasing vehicular traffic. In 2006 UWE hired its first travel planner, charged with developing and implementing a strategy to reduce travel to the campus by single occupancy vehicles. From 2007 onwards a range of policies have 
been progressively introduced to achieve that aim; bus services were improved through subsidised, tendered services and parking charges were introduced for students and staff.

The biggest changes were implemented between 2013 and 2015. The cost of annual student parking permits was increased from $£ 106$ to $£ 119$ per annum and the alternative daily charge was increased from $£ 0.75$ to $£ 3.00$. A 'no-permit zone' was also introduced covering central and northern Bristol, where most students live. Undergraduates who started at UWE after September 2013 became ineligible for campus parking permits if they lived within the 'no-permit zone' during term time. Exceptions could be made for students with disabilities or childcare commitments. Students who live on the campus are not allowed to park there. As this study concerns the impacts of destination parking constraints, the few third-year students who live on the campus were not included in the analysis reported below.

The capacity of the Frenchay car parks has never been a direct constraint. Although various changes have been made to the configuration of the car parks, it has always been possible for students with the right to park to find a space. A few students have been observed parking on the campus without authorisation, leading to a strengthening of enforcement measures. It is also possible to park on some residential streets around the campus, although the streets closest to the campus are subject to parking controls.

\section{Method}

The aim of the primary research was to identify whether the introduction of the parking restriction altered the travel behaviour of undergraduate students. This was examined through a survey of two successive cohorts of third year undergraduate 
students, administered in two waves, in Spring 2015 and Spring 2016. The majority of the first wave of third year students joined the university in September 2012, before the introduction of the campus parking restriction. The majority of the second wave of third year students joined the university in September 2013, immediately after the introduction of the campus parking restriction.

A paper questionnaire was designed to capture different aspects of the travel behaviour of the students, including licence-holding, car availability during term and vacation periods, campus parking permit-holding, travel mode to campus, and travel mode for the last non-campus trip. One or more of the third year undergraduate lectures were selected from each department represented on the Frenchay campus for inclusion in the sample frame. The questionnaires were distributed at the beginning of lectures, with students given a few minutes to complete them before returning them to a researcher, the lecturer or a box on the way out. The questionnaire content was deliberately minimised to reduce the completion time, and hence to boost the response rate, as well as to minimise disruption to the teaching schedule.

It had been anticipated that the two survey waves would capture the 'before and after' effects of the parking policy change. However, the progression of student cohorts from 2015 to 2016 was not as clear-cut as we had expected. Both waves contained a mixture of students starting either before or after the change in parking policy. The data from both waves was therefore pooled $(n=858)$ and the university start date (2012 or 2013) was used to identify whether students had started before or after the introduction of the parking constraint.

The dependent variables of interest included the following, expressed as the proportion of students: 
(i) with a driving licence available to them

(ii) with a car available in term time

(iii) with a car available in the vacation period

(iv) with a parking permit

(v) driving to campus

(vi) travelling to campus by public transport

(vii) driving on the last trip to a non-campus destination

Bivariate chi-square tests were used to identify statistically significant differences between the proportion of students performing each behaviour in the two groups: comparing the group starting 'before' to the group starting 'after' the introduction of the parking restriction. Note that the before and after survey sampling strategy had been designed to achieve two matched samples in terms of their demographic characteristics. Had this been achieved, a simple comparison of the proportion of students performing each behaviour would have been sufficient to address the research questions ${ }^{1}$. However, some differences in the demographic characteristics of the two groups were identified (described in section 5.1). The results of the chisquare tests were therefore checked against a series of binary logistic regression models estimated on each dependent variable. The regression models enabled us to control for a limited number of demographic characteristics including: gender, age, started before the introduction of the parking restriction, survey wave and live in the no-permit zone.

It is possible that the change in parking policy could have differing effects on the travel behaviours of male and female students, since there are well-established

\footnotetext{
${ }^{1}$ Note that the questionnaire was intentionally short to boost response rates and not designed to build comprehensive regression models of behaviour.
} 
associations between gender and various aspects of travel behaviour (Tilley and Houston, 2016). Chi-square tests were therefore also used to compare the travel behaviours of male and female students. Gender-specific effects of the policy change were identified by running the chi-square tests separately using (i) the subsample of students starting before the introduction of the parking restriction and (ii) the subsample of students starting after the introduction of the parking restriction.

\section{Results}

\subsection{Bivariate Analysis}

Table 1 presents the results of the chi-square tests comparing the characteristics of the two student groups: one starting before and one starting after the introduction of the parking restriction.

It is notable that the age profiles and the proportion of students living in the nopermit zone are the same for both groups. But there is a higher representation of females in the sub-sample starting after the introduction of the parking restriction. We return to this issue in section 5.3, when discussing the results of regression models which controlled for gender.

For all but one of the measures of travel behaviour tested, there is a statistically significant difference in the travel behaviour characteristics when comparing the 'after parking restriction' group to the 'before parking restriction' group. The one exception is 'using a car for the last (non-campus) trip' for which there was a small, but nonsignificant reduction in car use. 
Table 1: Travel behaviours before and after introduction of the parking restriction

\begin{tabular}{|c|c|c|c|c|c|c|c|}
\hline & \multicolumn{2}{|c|}{$\begin{array}{l}\text { Pooled } \\
\text { sample }\end{array}$} & \multicolumn{2}{|c|}{$\begin{array}{l}\text { Started before } \\
\text { parking } \\
\text { restriction }\end{array}$} & \multicolumn{2}{|c|}{$\begin{array}{l}\text { Started after } \\
\text { parking } \\
\text { restriction }\end{array}$} & \multirow[t]{2}{*}{$\begin{array}{c}\text { Chi-square } \\
\text { test }\end{array}$} \\
\hline & $\mathbf{n}$ & $\%$ & $\mathbf{n}$ & $\%$ & $\mathbf{n}$ & $\%$ & \\
\hline \multicolumn{8}{|l|}{ Gender } \\
\hline Female & 368 & 43.4 & 203 & 40.2 & 164 & 48.4 & $\chi 2=5.194$ \\
\hline Male & 480 & 56.6 & 302 & 59.8 & 175 & 51.6 & $p=0.023$ \\
\hline Total & 848 & 100.0 & 505 & 100.0 & 339 & 100.0 & $d f=1$ \\
\hline \multicolumn{8}{|l|}{ Age } \\
\hline Under 26 & 787 & 92.6 & 465 & 91.9 & 319 & 93.8 & $x^{2}=0.846$ \\
\hline Over 26 & 63 & 7.4 & 41 & 8.1 & 21 & 6.2 & $p=0.358$ \\
\hline Total & 850 & 100.0 & 506 & 100.0 & 340 & 100.0 & $d f=1$ \\
\hline \multicolumn{8}{|c|}{ Live in no-permit zone } \\
\hline Yes & 651 & 82.9 & 377 & 82.5 & 267 & 83.7 & $\chi 2=0.117$ \\
\hline No & 134 & 17.1 & 80 & 17.5 & 52 & 16.3 & $p=0.732$ \\
\hline Total & 785 & 100.0 & 457 & 100.0 & 319 & 100.0 & $d f=1$ \\
\hline \multicolumn{8}{|c|}{ Driving licence } \\
\hline Yes & 641 & 74.9 & 398 & 78.5 & 238 & 69.8 & $\chi 2=7.784$ \\
\hline No & 215 & 25.1 & 109 & 21.5 & 103 & 30.2 & $p=0.005$ \\
\hline Total & 856 & 100.0 & 507 & 100.0 & 341 & 100.0 & $d f=1$ \\
\hline \multicolumn{8}{|c|}{ Car available in term } \\
\hline Yes & 351 & 41.8 & 238 & 47.5 & 111 & 33.2 & $\chi 2=16.179$ \\
\hline No & 489 & 58.2 & 263 & 52.5 & 223 & 66.8 & $p<0.001$ \\
\hline Total & 840 & 100.0 & 501 & 100.0 & 334 & 100.0 & $d f=1$ \\
\hline \multicolumn{8}{|c|}{ Car available in vacation } \\
\hline Yes & 547 & 66.7 & 358 & 73.4 & 186 & 56.9 & $x 2=23.220$ \\
\hline No & 273 & 33.3 & 130 & 26.6 & 141 & 43.1 & $p<0.001$ \\
\hline Total & 820 & 100.0 & 488 & 100.0 & 327 & 100.0 & $d f=1$ \\
\hline \multicolumn{8}{|c|}{ Parking permit } \\
\hline Yes & 202 & 24.7 & 146 & 30.0 & 56 & 17.1 & $x 2=16.963$ \\
\hline No & 616 & 75.3 & 340 & 70.0 & 272 & 82.9 & $p<0.001$ \\
\hline Total & 818 & 100.0 & 486 & 100.0 & 328 & 100.0 & $d f=1$ \\
\hline \multicolumn{8}{|c|}{ Drive to campus } \\
\hline Yes & 245 & 29.1 & 164 & 33.0 & 80 & 23.8 & $x 2=7.734$ \\
\hline No & 598 & 70.9 & 333 & 67.0 & 256 & 76.2 & $p=0.005$ \\
\hline Total & 843 & 100.0 & 497 & 100.0 & 336 & 100.0 & $d f=1$ \\
\hline \multicolumn{8}{|c|}{ Public transport to campus } \\
\hline Yes & 326 & 38.7 & 163 & 32.8 & 158 & 47.0 & $x^{2}=16.536$ \\
\hline No & 517 & 61.3 & 334 & 67.2 & 178 & 53.0 & $\mathrm{p}<0.001$ \\
\hline Total & 843 & 100.0 & 497 & 100.0 & 336 & 100.0 & $d f=1$ \\
\hline \multicolumn{8}{|c|}{ Last trip driven } \\
\hline Yes & 288 & 33.8 & 181 & 35.8 & 106 & 31.4 & $\chi 2=1.616$ \\
\hline No & 563 & 66.2 & 324 & 64.2 & 232 & 68.6 & $p=0.204$ \\
\hline Total & 851 & 100.0 & 505 & 100.0 & 338 & 100.0 & $d f=1$ \\
\hline
\end{tabular}


The differences in the other measures of travel behaviours are in the expected direction; licence-holding, car availability and driving to campus were all lower amongst the group starting after the introduction of the parking restriction. Specifically, amongst the group of students starting after the parking restriction, as compared to the group of students starting before the parking restriction:

- Licence-holding was nine percentage points lower ;

- Car availability during the term was 14 percentage points lower;

- Car availability during the vacation was 16 percentage points lower;

- Driving to campus was nine percentage points lower; and

- Travelling to campus by public transport was 14 percentage points higher.

Note that the on-campus parking restriction did not apply to the minority of students living outside the no-permit zone (17 percent of our sample, $n=134$ ). We ran the same bivariate analysis on the subsample living outside the no permit zone and found no statistically significant associations between university start date and any of the measures of travel behaviour tested i.e. for students living outside the no-permit zone, the travel behaviours of students starting after the introduction of the parking restriction were no different to those starting before. Although some unobserved third factor cannot be entirely ruled out, this strengthens the principal observation that the change in parking policy was associated with declines in car access and licence-holding.

\subsection{Regression Analysis}

It was observed earlier that there was a higher representation of females in the group starting after the introduction of the parking restriction; and it is possible that gender could be a confounding factor, explaining part of the decline in car access 
amongst the group of students starting after the introduction of the parking restriction. This was checked by estimating regression models which control for a limited number of demographic characteristics. The results are summarised in Table 2.

Of the demographic controls included in the model, being female was significantly associated with a higher probability of public transport use to campus and a lower probability of licence-holding but was insignificant in the other regressions.

In relation to the effect of starting university after the introduction of the parking restriction, the results of the regression models are consistent with the bivariate tests. The parking restriction is associated with lower likelihood of holding a driving licence, lower likelihood of having a car available in the term and vacation periods, and lower likelihood of using a car to travel to campus or for the last trip. Specifically, starting after the parking restriction is associated with the odds of licence-holding, car availability and using a car to campus being reduced by a factor of a half or more. 
Table 2: Binary Logistic Regression Model Results

\begin{tabular}{|c|c|c|c|c|c|c|c|c|c|c|c|c|}
\hline & \multicolumn{12}{|c|}{ Dependent Variable } \\
\hline & \multicolumn{2}{|c|}{$\begin{array}{l}\text { Driving } \\
\text { Licence }\end{array}$} & \multicolumn{2}{|c|}{$\begin{array}{l}\text { Car Available } \\
\text { in Term }\end{array}$} & \multicolumn{2}{|c|}{$\begin{array}{l}\text { Car Available } \\
\text { in Vacation }\end{array}$} & \multicolumn{2}{|c|}{$\begin{array}{l}\text { Drive to } \\
\text { Campus }\end{array}$} & \multicolumn{2}{|c|}{$\begin{array}{c}\text { Public } \\
\text { Transport to } \\
\text { Campus }\end{array}$} & \multicolumn{2}{|c|}{$\begin{array}{l}\text { Last Trip } \\
\text { Driven }\end{array}$} \\
\hline & Odds & & Odds & & Odds & & Odds & & Odds & & Odds & \\
\hline & Ratio & $\mathbf{P}$ & Ratio & $\mathbf{P}$ & Ratio & $\mathbf{P}$ & Ratio & $\mathbf{P}$ & Ratio & $\mathbf{P}$ & Ratio & $\mathbf{P}$ \\
\hline $\begin{array}{l}\text { Started } \\
\text { after } \\
\text { parking } \\
\text { restriction }\end{array}$ & 0.548 & 0.002 & 0.403 & 0.000 & 0.346 & 0.000 & 0.502 & 0.001 & 2.268 & 0.000 & 0.629 & 0.014 \\
\hline $\begin{array}{l}\text { Survey } \\
\text { wave: } \\
2016\end{array}$ & 1.578 & 0.022 & 1.756 & 0.002 & 1.904 & 0.001 & 1.519 & 0.036 & 0.605 & 0.006 & 1.645 & 0.007 \\
\hline $\begin{array}{l}\text { Live in no- } \\
\text { permit } \\
\text { zone }\end{array}$ & 0.457 & 0.004 & 0.238 & 0.000 & 0.312 & 0.000 & 0.135 & 0.000 & 2.975 & 0.000 & 0.237 & 0.000 \\
\hline Female & 0.573 & 0.001 & 0.790 & 0.133 & 0.758 & 0.088 & 0.827 & 0.284 & 1.609 & 0.002 & 0.816 & 0.209 \\
\hline Under 26 & 1.013 & 0.972 & 1.319 & 0.384 & 1.856 & 0.059 & 1.015 & 0.965 & 1.246 & 0.518 & 1.932 & 0.045 \\
\hline Constant & 5.033 & 0.001 & 1.267 & 0.565 & 2.098 & 0.090 & 1.520 & 0.344 & 0.239 & 0.001 & 0.569 & 0.176 \\
\hline & $n=773$ & & $n=761$ & & $\mathrm{n}=742$ & & $\mathrm{n}=760$ & & $n=760$ & & $\mathrm{n}=770$ & \\
\hline & $\begin{array}{l}x 2=33 \\
d f=5\end{array}$ & & $\begin{array}{l}\chi 2=79 \\
d f=5\end{array}$ & & $\begin{array}{l}\chi 2=60 \\
d f=5\end{array}$ & & $\begin{array}{l}\chi 2=11 \\
d f=5\end{array}$ & $62^{\wedge}$ & $\begin{array}{l}\chi 2=60 . \\
d f=5\end{array}$ & & $\begin{array}{l}\chi 2=62 . \\
d f=5\end{array}$ & \\
\hline
\end{tabular}

Notes:

${ }^{\wedge}$ Chi-square statistic is significant at $95 \%$ level, indicating improved model fit compared to null model

\subsection{Analysis by Gender}

The final analysis was designed to examine whether the parking policy had differing effects on male and female students. The results of chi-square tests comparing the travel behaviours of male and female students (separately for the groups starting before / after the policy change) are summarised in Table 3.

There were no significant differences between the travel behaviours of male and female students within the group starting before the introduction of the parking restriction, although it is notable that a slightly higher proportion of female students held a parking permit compared to males. This situation was markedly different within the group starting after the introduction of the parking restriction. Amongst this 
subsample (compared to males), females were less likely to hold a driving licence, less likely to have access to a car during the term and vacation periods, less likely to have driven to campus / for the last (non-campus) trip, and more likely to have used public transport to travel to campus. This suggests that the parking policy had a stronger influence on the travel behaviour of female students as compared to male students. We discuss possible reasons for this in the next section.

Table 3: Comparison of males and females, starting before and after intervention

\begin{tabular}{|c|c|c|c|c|c|c|c|c|}
\hline \multirow[b]{2}{*}{ Travel Behaviour } & \multicolumn{4}{|c|}{ Started before parking restriction } & \multicolumn{4}{|c|}{ Started after parking restriction } \\
\hline & Total & Male & Fem. & $\begin{array}{l}\text { Chi- } \\
\text { square } \\
\text { test }\end{array}$ & Total & Male & Fem. & $\begin{array}{c}\text { Chi-square } \\
\text { test }\end{array}$ \\
\hline Driving licence (n) & 505 & 302 & 203 & $\chi^{2}=1.572$ & 339 & 175 & 164 & $x^{2}=15.633$ \\
\hline Yes (\%) & 78.4 & 80.5 & 75.4 & $p=0.210$ & 70.2 & 80.0 & 59.8 & $p<0.001$ \\
\hline No (\%) & 21.6 & 19.5 & 24.6 & $d f=1$ & 29.8 & 20.0 & 40.2 & $d f=1$ \\
\hline $\begin{array}{l}\text { Car available in term } \\
\text { (n) }\end{array}$ & 499 & 299 & 200 & $\chi^{2}=0.009$ & 333 & 174 & 159 & $\chi^{2}=8.463$ \\
\hline Yes (\%) & 47.5 & 47.2 & 48.0 & $p=0.926$ & 33.3 & 40.8 & 25.2 & $p=0.004$ \\
\hline No (\%) & 52.5 & 52.8 & 52.0 & $d f=1$ & 66.7 & 59.2 & 74.8 & $d f=1$ \\
\hline $\begin{array}{l}\text { Car available in } \\
\text { vacation }(\mathrm{n})\end{array}$ & 487 & 294 & 193 & $\chi^{2}=0.000$ & 325 & 171 & 154 & $\chi^{2}=8.719$ \\
\hline Yes (\%) & 73.3 & 73.1 & 73.6 & $p=0.997$ & 56.9 & 64.9 & 48.1 & $p=0.003$ \\
\hline No (\%) & 26.7 & 26.9 & 26.4 & $d f=1$ & 43.1 & 35.1 & 51.9 & $\mathrm{df}=1$ \\
\hline Parking permit (n) & 485 & 290 & 195 & $\chi^{2}=3.156$ & 326 & 171 & 155 & $\chi^{2}=0.391$ \\
\hline Yes (\%) & 30.1 & 26.9 & 34.9 & $p=0.076$ & 17.2 & 18.7 & 15.5 & $p=0.532$ \\
\hline No (\%) & 69.9 & 73.1 & 65.1 & $d f=1$ & 82.8 & 81.3 & 84.5 & $d f=1$ \\
\hline $\begin{array}{l}\text { Drive to campus today } \\
\text { (n) }\end{array}$ & 496 & 294 & 202 & $\chi^{2}=0.277$ & 334 & 171 & 163 & $\chi^{2}=10.348$ \\
\hline Yes (\%) & 33.1 & 32.0 & 34.7 & $p=0.599$ & 24.0 & 31.6 & 16.0 & $p=0.001$ \\
\hline No (\%) & 66.9 & 68.0 & 65.3 & $d f=1$ & 76.0 & 68.4 & 84.0 & $d f=1$ \\
\hline $\begin{array}{l}\text { Public transport to } \\
\text { campus }(n)\end{array}$ & 496 & 294 & 202 & $\chi^{2}=2.150$ & 334 & 171 & 163 & $\chi^{2}=12.131$ \\
\hline Yes (\%) & 32.7 & 29.9 & 36.6 & $p=0.143$ & 47.0 & 37.4 & 57.1 & $p<0.001$ \\
\hline No (\%) & 67.3 & 70.1 & 63.4 & $d f=1$ & 53.0 & 62.6 & 42.9 & $d f=1$ \\
\hline Last trip driven (n) & 503 & 301 & 202 & $\chi^{2}=0.051$ & 336 & 173 & 163 & $\chi^{2}=6.583$ \\
\hline Yes (\%) & 36.0 & 36.5 & 35.1 & $p=0.822$ & 31.5 & 38.2 & 24.5 & $p=0.010$ \\
\hline No (\%) & 64.0 & 63.5 & 64.9 & $d f=1$ & 68.5 & 61.8 & 75.5 & $d f=1$ \\
\hline
\end{tabular}




\section{Discussion}

The lower levels of driving to the campus amongst those who started after the parking restriction re-affirmed the findings of the literature that removing the right to park at a destination does reduce driving to it. Of greater significance is the finding that licence-holding and car availability were all substantially lower amongst those who started after the change in policy. Licence-holding was nine percentage points lower amongst the group starting after the parking restriction (79 percent compared to 70 percent - Table 1). Car availability during term time was 15 percentage points lower (48 percent compared to 33 percent - Table 1). The same pattern also applied to travel to other destinations for other purposes in the multi-variate regression, although the bivariate difference was not statistically significant.

The lower share of driving amongst those who started after the parking restriction was entirely accounted for by higher use of public transport; their use of other modes were slightly lower. This is probably because of the discounted bus season tickets available to students; once purchased they enable bus travel at zero marginal cost.

In seeking explanations for the difference in car ownership and licence-holding, it should be noted that most of the students surveyed had been studying at UWE for more than two years. It is likely that a ban on parking on campus would have consciously or unconsciously dissuaded some students from acquiring a car over that time period. As noted in Section 2.3, most young adults aged 17 to 20 do not yet hold driving licences; the average age of licence-acquisition in Southwest England was 21 in 2011 (DfT, 2012). It is plausible, therefore, that the parking ban might have dissuaded some students from learning to drive and acquiring driving licences during their time at UWE. 
An alternative hypothesis - difficult to rule out in any natural experiment - is that unobserved differences between the two intakes, one starting before and one starting after the introduction of the parking restriction, might explain all of the variations in travel behaviour. If the change in policy had dissuaded some applicants with pro-car preferences from studying at the university, this could account for some or all of those variations. This study was not able to measure that directly, but indirect evidence suggested that it was unlikely to explain much of the variations, if any. Following the introduction of the policy undergraduate applications to UWE rose by five percent, suggesting that it was not a significant deterrent. UCAS (2016) surveyed 16,600 university applicants across the UK. One of the questions in that survey asked applicants why they chose not to apply to a list of named universities, not including UWE, but including others with similar parking restrictions. This revealed that 13 percent entered "other" reasons, of which 0.1 percent mentioned travel or transport reasons; none mentioned parking (Taylor, Rachel, UCAS Media, email to Steve Melia October $\left.4^{\text {th }}\right)$. This is consistent with the observations of UWE's admissions manager and travel planner who had encountered queries and complaints related to parking, but no cases where these had caused anyone to leave the university or withdraw an application.

The stability in the proportions of students living inside and outside the nopermit zone (Table 1) suggests that the change in policy did not influence students' residential location decisions. Amongst those living inside the no-permit zone those who started after the introduction of the parking restriction displayed significantly different behaviour from those who started before, whereas no such differences were found amongst those outside the no-permit zone. This suggests, although it may not 
prove, that the change in parking policy did indeed influence car ownership and licenceholding.

In seeking to explain the gender differences it may be noted that females were more likely to park on campus than males (a further analysis indicated that 86 percent of all females who drove parked on campus, compared to 66 percent of male drivers). On the other hand males without a parking permit were more likely to drive to campus than females (18 percent of males compared to eight percent of females). We did not specifically probe the reasons for this gender difference but some observations from the literature suggest one possibility. A large body of literature has found a greater propensity amongst males to commit driving violations (for example Maxwell et al., 2005 provide evidence of this using a sample of students in the UK) and specifically to defy parking restrictions (e.g. Fletcher, 1995). The travel planner indicated that most of the cases of unauthorised parking they have encountered on campus have involved male students so it is plausible that the policy to remove parking rights on campus provoked strategies to circumvent the parking restrictions amongst more males than females. It is also possible that parking off-campus might raise more security concerns amongst females, although the residential streets surrounding the campus are quiet and suburban in nature.

\section{Conclusions}

This study supports the well-established finding that removing the right to park at a destination reduces driving to that destination. The policy change was associated with a lower modal share of driving to campus of nine percentage points. Concerns that a no-permit zone might discourage applications to study at the university or provide an incentive for people to live further away were not borne out by this study. The study 
also found that the no-parking rule had greater impact on the travel behaviour of females than males, consistent with the literature on driving violations that males are more likely to circumvent parking restrictions, where possible.

The study has shown that parking restrictions at a regular destination were associated with lower licence-holding, car availability and driving for other purposes amongst students starting after the parking restriction, compared to those starting before. Car availability during term-time was 15 percentage points lower and licenceholding was nine percentage points lower. These findings have important implications for research across a wider range of contexts, subject to the caveats about causality and generalisability, discussed below. Licence-holding is often treated as an exogenous variable in models of travel behaviour but if parking constraints can influence levels of licence-holding, then more sophisticated models of travel behaviour may need to reflect that endogeneity. A similar point may be made about the effect of parking availability on the decision to acquire a car although the endogeneity of that factor has been more widely recognised (e.g. Van Acker and Witlox, 2010).

Overall, the results suggest that removing the right to park on a university campus had the effect of delaying the acquisition of driving licences and privately owned cars amongst young adults. As many universities have parking restrictions of varying kinds, this finding, coupled with rising participation in higher education, may explain part of the observed fall in licence-holding amongst young adults in the UK and other developed countries in recent decades.

The chosen research method did impose some limitations. The questionnaires were designed for ease of rapid completion, due to time constraints at the beginning of lectures. This limited the range of measures included in the questionnaire and these were not sufficient to build a complete explanatory model of modal choice or car 
ownership. The causal inferences drawn from the findings above must therefore be tentative. To what extent the findings may be generalised from students travelling to a campus, to other groups, such as employees, or other types of destination would merit further research. It may be reasonable to infer that a restriction or discouragement to drive to study leads to lower car ownership and therefore less driving in general, although the nature of the causal processes through which people respond to parking constraints is worthy of further investigation, possibly using qualitative methods.

For policymakers, these findings suggest that constraints on destination parking may help to reinforce efforts to reduce parking pressures and traffic generation across a city or a sub-region.

\section{References:}

BEIS, (2016) Typical Retail Prices of Petroleum Products and a Crude Oil Price Index [online]. www.gov.uk: Department of Business, Energy and Industrial Strategy. [Accessed October 2016].

Cairns, S., Newson, C. and Davis, A. (2010) Understanding successful workplace travel initiatives in the UK. Transportation Research Part A: Policy and Practice. 44 (7), pp. 473-494.

Carse, A., Goodman, A., Mackett, R.L., Panter, J. and Ogilvie, D. (2013) The factors influencing car use in a cycle-friendly city: the case of Cambridge. Journal of Transport Geography. 28 (0), pp. 67-74.

Chatterjee, K., Clark, B. and Bartle, C. (2016) Commute mode choice dynamics: Accounting for day-to-day variability in longer term change. European Journal of Transport and Infrastructure Research. 16 (4), pp. 713-734.

Chatterjee, K., Goodwin, P., Schwanen, T., Clark, B., Jain, J., Melia, S., Middleton, J., Plyushteva, A., Ricci, M., Santos, G. and Stokes, G. (2018) Young people's travel What's changed and why? Review and analysis. Project Report. Department for Transport, Bristol

Clegg, R. (2007) Empirical studies on road traffic response to capacity reduction. In: Allsop, R., ed. (2007) The 17th International Symposium on Transportation and Traffic Theory [online]. London, Elsevier.

DfT (2012) Average age of candidates passing their car driving test, 2007 to 2011. Freedom of Information Act Release. [Online] 
https://www.gov.uk/government/publications/average-age-of-candidates-passing-theircar-practical-driving-test [Accessed 30th April 2018]

DfT, (2015) Full car driving licence holders aged 17-20 by gender: England, 1989/91 to 2015. Table NTS0202 [online]

https://www.gov.uk/government/uploads/system/uploads/attachment_data/file/550635/n ts0202.xls [Accessed 28th February 2016].

DfT, (2016a) Annual Bus Statistics, England 2015/16 [online]. www.gov.uk:

Department for Transport. [Accessed October 2016].

DfT, (2016b) Provisional Road Estimates Great Britain: July 2015 to June 2016

[online]. www.gov.uk: Department for Transport. [Accessed October 2016].

Fletcher, D. (1995) A five-year study of effects of fines, gender, race, and age on illegal parking in spaces reserved for people with disabilities. Rehabilitation Psychology. 40 (3), pp. 203-210.

Goodwin, P. (1996) Empirical evidence on induced traffic. Transportation. 23 (1), pp. $35-54$.

Goodwin, P. and Van Dender, K. (2013) 'Peak Car' - Themes and Issues. Transport Reviews. 33 (3), pp. 243-254.

Guo, Z. (2013) Does residential parking supply affect household car ownership? The case of New York City. Journal of Transport Geography. 26 (0), pp. 18-28.

Hensher, D.A. and King, J. (2001) Parking demand and responsiveness to supply, pricing and location in the Sydney central business district. Transportation Research Part A: Policy and Practice. 35 (3), pp. 177-196.

Kelly, J.A. and Clinch, J.P. (2006) Influence of varied parking tariffs on parking occupancy levels by trip purpose. Transport Policy. 13 (6), pp. 487-495.

Li, Z., Huang, H., Lam, W.H.K. and Wong, S.C. (2007) A Model for Evaluation of Transport Policies in Multimodal Networks with Road and Parking Capacity Constraints. Journal of Mathematical Modelling and Algorithms. 6 (2), pp. 239-257.

Maxwell, J.P., Grant, S. and Lipkin, S. (2005) Further validation of the propensity for angry driving scale in British drivers. Personality and Individual Differences. 38 (1), pp. 213-224.

McCahill, C. and Garrick, N. (2014) Parking Supply and Urban Impacts. In: Ison, S.G. and Mulley, C., eds. (2014) Parking: Issues and Policies. Bingley,West Yorkshire: Emerald Insight, pp. 33-56.

McCahill, C., Garrick, N., Atkinson-Palombo, C. and Polinski, A. (2015) Effects of Parking Provision on Automobile Use in Cities: Inferring Causality. In: Anon. (2015) Transportation Research Board Annual Meeting. Washington DC, January 2016. 
Melia, S. (2015) Do randomised control trials offer a solution to 'low quality' transport research? World Transport Policy and Practice. 21 (2), pp. 64-71.

Melia, S. (2014) Carfree and Low Car Development. In: Ison, S.G. and Mulley, C., eds. (2014) Parking: Issues and Policies. Bingley,West Yorkshire: Emerald Insight, pp. 213234.

Milosavljević, N. and Simićević, J. (2016) User response to parking policy change: A comparison of stated and revealed preference data. Transport Policy. 46 pp. 40-45.

Newman, P. and Kenworthy, J. (1999) Sustainability and Cities: Overcoming Automobile Dependence. Island press.

Petrunoff, N., Rissel, C., Wen, L.M. and Martin, J. (2015) Carrots and sticks vs carrots: Comparing approaches to workplace travel plans using disincentives for driving and incentives for active travel. Journal of Transport \& Health. 2 (4), pp. 563-567.

RAC Foundation (2005) Motoring Towards 2050: Parking in Transport Policy. London: RAC Foundation.

Riggs, W. (2014) Dealing with parking issues on an urban campus: The case of UC Berkeley. Case Studies on Transport Policy. 2 (3), pp. 168-176.

Rye, T., Cowan, T. and Ison, S.G. (2006) Expansion of a Controlled Parking Zone (CPZ) and its Influence on Modal Split: The Case of Edinburgh. Transportation Planning and Technology. 29 (1), pp. 75-89.

Shoup, D.C. (2005) The High Cost of Free Parking. Planners Press, American Planning Association.

Tilley, S. and Houston, D. (2016) The gender turnaround: Young women now travelling more than young men. Journal of Transport Geography. 54 pp. 349-358.

UCAS, (2016) Through the Lens of Students - how Perceptions of Higher Education Influence Applicants' Choices [online]. www.ucas.com: Universities and Colleges Admissions Service. [Accessed September 2017].

Van Acker, V. and Witlox, F. (2010) Car ownership as a mediating variable in car travel behaviour research using a structural equation modelling approach to identify its dual relationship. Journal of Transport Geography. 18 (1), pp. 65-74.

Weinberger, R. (2012) Death by a thousand curb-cuts: Evidence on the effect of minimum parking requirements on the choice to drive. Transport Policy. 20 pp. 93-102.

Whalen, K.E., Páez, A. and Carrasco, J.A. (2013) Mode choice of university students commuting to school and the role of active travel. Journal of Transport Geography. 31 pp. 132-142. 